\title{
Propylthiouracil prevents cutaneous and pulmonary fibrosis in the reactive oxygen species murine model of systemic sclerosis
}

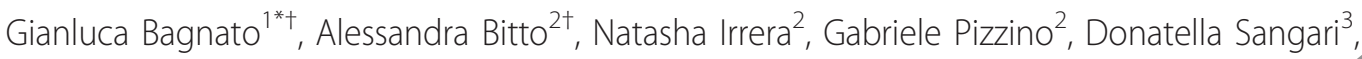
Maurizio Cinquegrani ${ }^{1}$, William Neal Roberts ${ }^{4}$, Marco Atteritano $^{3}$, Domenica Altavilla ${ }^{2}$, Franc sco Squad, $\mathbf{L O}^{2}$, Gianfilippo Bagnato ${ }^{3}$ and Antonino Saitta ${ }^{1}$

\begin{abstract}
Introduction: Recent advances suggest that the cellular redox state may play significont role in the progression of fibrosis in systemic sclerosis (SSc). Another, and as yet poorly accounte or r of SSc is its overlap with thyroid abnormalities. Previous reports demonstrate that hypothyroidism rea s oxidant stress. The aim of this study was therefore to evaluate the effect of propylthiouracil (PTU), of the, rypothyroidism induced by it, on the development of cutaneous and pulmonary fibrosis in the oxidant stresy, nurine model of SSC.

Methods: Chronic oxidant stress SSC was induced in BALB/C mice by daily subcutaneous injections of hypochlorous acid $(\mathrm{HOCl})$ for 6 weeks. Mice $(n=25)$ wer ran nized into three arms: $\mathrm{HOCl}(n=10), \mathrm{HOCl}$ plus PTU $(n=10)$ or vehicle alone $(n=5)$. PTU administration $n$ in ated 30 minutes after $\mathrm{HOCl}$ subcutaneous injection and continued daily for 6 weeks. Skin and 1ung fib, were evaluated by histologic methods.

Immunohistochemical staining for alpha-smooth $a$ adtin ( $\alpha$-SMA) in cutaneous and pulmonary tissues was performed to evaluate myofibroblast differentration. a and skin concentrations of vascular endothelial growth factor (VEGF), extracellular signal-related kinas (ERK), ra, sarcoma protein (Ras), Ras homolog gene family (Rho), and transforming growth factor (TGF) $\beta$ were analyz by Western blot.

Results: Injections of $\mathrm{HOCl}$ induced utaneous and lung fibrosis in BALB/C mice. PTU treatment prevented both dermal and pulmonary fibrosis. Myo roblast)differentiation was also inhibited by PTU in the skin and lung. The increase in cutaneous and pulmonary cSsion of VEGF, ERK, Ras, and Rho in mice treated with $\mathrm{HOCl}$ was significantly prevented in mice ouministered with PTU.

Conclusions: PTU, prob ${ }^{-1}$ through its direct effect on reactive oxygen species or indirectly through thyroid function inhibition, $p$ ver s the fevelopment of cutaneous and pulmonary fibrosis by blocking the activation of the Ras-ERK pathy is ne oxidant-stress animal model of SSc.
\end{abstract}

\section{Introduction}

Theorie ${ }^{c} \mathrm{~s}$ ' eroterma pathogenesis accommodate three fundamen and/ong-standing observations about syste nic cleros, (SSc): its vascular nature, its abnormal fib tivation, and the immune-mediated damage [1]. L wite of a significant effort, the etiopathogenesis of

\footnotetext{
* Correspondence: gbagnato@unime.it

† Contributed equally

${ }^{1}$ Department of Clinical and Experimental Medicine, Division of Internal Medicine, University of Messina, Via Consolare Valeria n¹, 98100, Messina, Italy

Full list of author information is available at the end of the article
}

SSc remains unknown. A link between reactive oxygen species and pathogenesis of scleroderma has been explored [2]. Oxidative stress may directly or indirectly stimulate the accumulation of extracellular matrix proteins. Conversely, fibrosis may contribute to oxidative stress, or both of them may be triggered by an independent mechanism. Indirect proof of abnormal oxidative stress was provided by Dooley et al. [3], who showed that the antioxidant epigallocatechin-3-gallate can reduce extracellular matrix production and inhibit contraction of dermal fibroblasts from systemic sclerosis patients. Furthermore,
C Biomed Central

() 2013 Bagnato et al.; licensee BioMed Central Ltd. This is an open access article distributed under the terms of the Creative Commons Attribution License (http://creativecommons.org/licenses/by/2.0), which permits unrestricted use, distribution, and reproduction in any medium, provided the original work is properly cited. 
epigallocatechin-3-gallate was able to suppress intracellular reactive oxygen species (ROS), extracellular signalregulated kinases (ERK1-2) signaling, and nuclear factor kappa-light-chain-enhancer of activated B cells (NF- $\kappa \mathrm{B})$ activity [4]. ERK, one of the relevant targets of ROS, and its upstream mediators, such as Ras family proteins, function as key molecules in the pathway that leads to fibrosis, and in maintaining the generation and amplification of ROS. Levels of ROS and type I collagen were significantly higher, and amounts of free thiol were significantly lower in SSc fibroblasts compared with normal fibroblasts [5]. Hormonal influences on the etiopathogenesis of the disease have been intensively studied, focusing on disturbances of the gonadal axis [6,7]. A second, and as yet poorly accounted for, endocrine feature of scleroderma is its overlap with thyroid abnormalities [8]. Of 719 patients affected by SSc, 273 (38\%) had at least one other autoimmune disease, with the most frequent being autoimmune thyroid disease (AITD) [9]. Whereas the association of Graves disease with SSc $[10,11]$ is supported by case reports, the literature related to Hashimoto thyroiditis and hypothyroidism in general, either subclinical or symptomatic, in SSc patients is more robust [12]. It was recently demonstrated by Cianfarani et al. [13] that thyroid-stimulating hormone (TSH)-receptor messenger RNA is consistently detected in both skin biopsies and cultured prin ary keratinocytes and, more interestingly, in dermal fibr las's of patients with SSc. A previous report confi-nea e occurrence of a state of oxidizing stress in lation hyperthyroidism [14].

The aim of the study was, therefore, to evalua, the effect of propylthiouracil (PTU), adn nistered at a dose able to induce hypothyroidism, on th $x$ ten of fibrosis in a murine model of SSc, base $n$ reactive oxygen species-mediated injury.

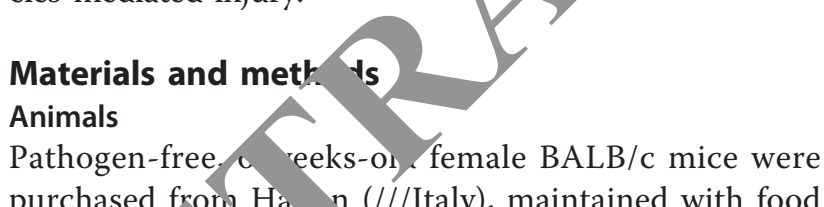
purchased from $\mathrm{Ha}$ n (///Italy), maintained with food and wate ad libitum, and given human care according to institu "argu delines. The project was reviewed and app d by Ethics Committee of the University of ssi a All mice were housed in single cages under con Jllea light and temperature conditions. Mice $(n=$ 25) w e randomized in three arms: $\mathrm{HOCl}$ alone $(n=$ $10), \mathrm{HOCl}$ plus propylthiouracil $(n=10$; hereinafter PTU), or vehicle alone ( $n=5$; subsequently SHAM) for 6 weeks.

\section{ROS preparation and treatments}

SSc was induced as characterized in detail in the Cochin chronic oxidant stress model [15]. In brief, hypochlorous acid $(\mathrm{HOCl})$ was produced by adding $166 \mu \mathrm{l}$ of sodium hypochlorite $(\mathrm{NaClO})$ solution (2.6\% as active chlorine) to $11.1 \mathrm{ml}$ of potassium hydrogen phosphate $\left(\mathrm{KH}_{2} \mathrm{PO}_{4}\right)$ solution (100 mM; pH 7.2). A total of $100 \mu \mathrm{l}$ of solution containing $\mathrm{HOCl}$ was injected s.c. into the back of the mice, by using a 27-gauge needle, every day for 6 weeks. Mice $(n=10)$ from the $\mathrm{HOCl}$ group $(n=20)$ were randomly chosen to be treated with propylth ouracil (Sigma-Aldrich, Italy///) at the dose of $12 \% / \mathrm{k} /$ dar. The dosage of $12 \mathrm{mg} / \mathrm{kg} /$ day was chosen as be consistent with the report from the Eur hean Med, 1 nes Agency recommendations on propylthio cil, $b$ ased on previously published studies. The method a PTU-dosing regimen for reliably reproc cing the hypothyroid state in mice is well establic $d$ in o li erature [16-20]. PTU administration was init 30 minutes after the $\mathrm{HOCl}$ subcutaneoup iection, and continued for 6 weeks. All agents were p. ared fresh daily. Sham-treated animals rea ed inje,tions of $100 \mu \mathrm{l}$ of saline solution.

\section{Experime ${ }^{-1}$ proce are}

At the ent on experiment, animals were killed with an overdos of pentothal sodium $(80 \mathrm{mg} / \mathrm{kg} /$ intraperitoII. v). Serum samples were collected by cardiac puncture om each mouse and stored at $-80^{\circ} \mathrm{C}$ until use. nos were removed from each mouse, and a small pisce immediately stored for Western blot at $-80^{\circ} \mathrm{C}$ until ase, whereas the rest was collected for histopathology, inflated with $400 \mu \mathrm{l}$ of $10 \%$ formalin/PBS, and fixed in formalin for 24 hours. After paraffin embedding, 5- $\mu \mathrm{m}$ sections were cut throughout the whole lung. Five sections, with 1-mm intervals, were stained with Masson Trichrome (MT), and systematically scanned with a light microscope, as previously described [21,22]. A skin biopsy was performed on the back region, involving the skin of the injected area, and stored at $-80^{\circ} \mathrm{C}$ for protein expression or fixed in $10 \%$ neutral buffered formalin for histopathologic analysis.

\section{Determination of Rho, Ras, ERK, and VEGF by Western blot analysis}

Lung and skin samples were homogenized in radioimmunoprecipitation assay (RIPA) buffer $(25 \mathrm{~m} M$ Tris/HCl, pH 7.4; $1.0 \mathrm{~m} M$ EGTA; $1.0 \mathrm{~m} M$ EDTA) added with $1 \%$ of Nonidet P40, $0.5 \%$ of phenyl methylsulfonyl fluoride (PMSF), aprotinin, leupeptin, and peptastatin $(10 \mu \mathrm{g} / \mathrm{ml}$ each), with a Ultra Turrax (IKA, Staufen, Germany) homogenizer. The lysate was subjected to centrifugation at $15.000 \mathrm{rpm}$ for 15 minutes at $4^{\circ} \mathrm{C}$. The supernatant was collected and used for protein determination with the BioRad DC protein assay kit (Bio-Rad, Richmond, CA, USA). Protein samples $(30 \mu \mathrm{g})$ were denatured in reducing buffer (62 $\mathrm{m} M$ Tris pH 6.8, 10\% glycerol, 2\% SDS, $5 \% \beta$-mercaptoethanol, $0.003 \%$ bromophenol blue), and separated by 
electrophoresis on an SDS (12\%) polyacrylamide gel. The separated proteins were transferred on to a PVDF membrane (Amersham, UK), by using the transfer buffer (39 $\mathrm{m} M$ glycine, $48 \mathrm{~m} M$ Tris $\mathrm{pH} 8.3,20 \%$ methanol) at 100 $\mathrm{mA}$ for 1 hour. The membranes were blocked with $5 \%$ non-fat dry milk (Bio-Rad) in TBS- $0.1 \%$ Tween for 1 hour at room temperature, washed 3 times for 10 minutes each in TBS- $0.1 \%$ Tween, and incubated overnight at $4^{\circ} \mathrm{C}$ with a primary Rho or Ras (Abcam, Cambridge, UK), or ERK, or p-ERK (Cell Signaling, Danvers, MA, USA), or VEGF (Abcam) antibody in TBS-0.1\% Tween. After being washed 3 times for 10 minutes each in TBS-0.1\% Tween, the membranes were incubated with a peroxidase-conjugated secondary antibody (Pierce, UK) for 1 hour at room temperature. After washing, the membranes were analyzed with the enhanced chemiluminescence system according to the manufacture's protocol (ECL-plus, Amersham, UK). The protein signal was quantified with scanning densitometry by using a bio-image analysis system (Bio-Profil, Milan, Italy). The results from each experimental group were expressed as relative integrated intensity compared with Sham lung or skin tissue measured within the same batch. $\beta$-Actin (Cell Signalling) was used on stripped blots to confirm equal protein loading.

\section{ELISA of serum levels of total $\mathrm{T}_{3}$ and $\mathrm{T}_{4}$ and TSH}

Whole blood was collected from the mice and a wed to clot. The serum was used in ELISA assays to nea total $\mathrm{T}_{3}$, total $\mathrm{T}_{4}$, and TSH (Mouse Ultr. nsitivi Thyroxine, u-T3 ELISA Kit; Mouse Ultrase itivity Thyroxine, u-T4 ELISA Kit and Moase ultrase sitive thyroid-stimulating hormone, U $\Gamma \mathrm{SH}$ EIISA Kit, MyBiosource, San Diego, CA, USA)

Histologic and immunohistochemica ruation of mice At the end of the expental phase, lungs and skin were removed from ar mols and fixed in 10\% buffered formalin, process for paraffin embedding, sectioned at $5-\mu \mathrm{m} / \mathrm{kness}$, a d subsequently stained with $H \& E$ or Masson $t_{1}$ hrome, for examination under a light mic oscope. For immunohistochemistry, paraffinembedat tosue were sectioned $(5 \mu \mathrm{m})$, rehydrated, and igen 1 ieval was performed by using $0.05 \mathrm{M}$ $s$ Jiur citrace buffer. Tissues were treated with $1 \%$ hy a gen peroxide to block endogenous peroxidase activis and with horse normal serum (Vector Laboratories, Burlingame, CA, USA) to prevent nonspecific staining. A primary antibody against $\alpha$-SMA (Abcam, Cambridge, UK) was used and kept overnight at $4^{\circ} \mathrm{C}$ in a humid box. After washing in PBS, a secondary antibody was used (Vector Laboratories), and the location of the reaction was visualized with diaminobenzidine tetra-hydrochloride (Sigma-Aldrich, Milan, Italy). Slides were counterstained with hematoxylin, dehydrated, and mounted with coverslips. As a part of the histologic evaluation, all slides were examined by a pathologist without knowledge of the previous treatment, by using masked slides from $\times 5$ to $\times 40$ magnification with a Leica (Leica Microsystems, Milan, Italy) microscope.

\section{Measurement of pulmonary MPO activity in mice}

Myeloperoxidase activity was determined in $h, t$ sues, after being homogenized in a solution contain $0.5 \%$ hexa-decyl-trimethylammonium bromir' dissolved, $\mathrm{M} 10$ $\mathrm{m} m$ potassium phosphate buffer $(\mathrm{pH} 7 . \mathrm{b}$, nd th en centrifuged for 30 minutes at $20,000 \mathrm{~g}$ at $4^{\circ} \mathrm{C}$. aliquot of the supernatant was allowed to act with a solution of tetra-methyl-benzidine $(1.6 \mathrm{~m})$, and $0.1 \mathrm{~mm} \mathrm{H} \mathrm{H}_{2} \mathrm{O}_{2}$. The rate of change in zocor ce was measured with spectrophotometry at $n$ nm. $N_{1} \zeta$ activity was defined as the quantity of enzyn degrading $1 \mu \mathrm{mol}$ hydrogen peroxide/min at and wa, expressed in units per 100 mg of tissue

\section{Assessme of derm, thickness in mice}

Dermal thlicksin $\sigma$, defined as the thickness of skin from the top of the granular layer to the junction between the a. is and s.c. fat, was examined in histologic samples (Mas on trichrome stain) by using the Leica application te software, as previously described $[23,24]$. Ten rando, n measurements were taken per section. The results were expressed in micrometers as mean values of dermal thickness for each group. Two investigators in a blinded fashion examined all the sections, independently.

\section{Assessment of pulmonary fibrosis in mice}

The degree of pulmonary fibrosis was evaluated in H\&Estained sections by using the Ashcroft score [25] (0, normal; 1 , minimal fibrotic thickening of alveolar walls; 2 , moderate thickening of walls without obvious damage to lung architecture; 3 , increased fibrosis with definite damage to lung structure and formation of fibrous bands or small fibrous masses; and 4, severe distortion of structure and large fibrous areas. Two pathologists performed all histologic evaluations in a blinded fashion.

\section{Statistical analysis}

All quantitative data are expressed as mean \pm SD for each group. Data were compared by using the nonparametric Mann-Whitney test or the Student paired $t$ test. When the analysis included more than two groups, oneway analysis of variance was used. $P$ values $<0.05$ were considered significant.

\section{Results}

\section{Propylthiouracil administration abated thyroid function}

Propylthiouracil, at the dose of $12 \mathrm{mg} / \mathrm{kg} / \mathrm{s}$.c./day, determined the inhibition of thyroid function in treated mice 
Table 1 Effects of PTU on serum thyroid hormone levels.

\begin{tabular}{lcccl}
\hline & $\begin{array}{c}\text { Sham } \\
(\boldsymbol{n}=\mathbf{5})\end{array}$ & $\begin{array}{c}\mathrm{HOCl} \\
(\boldsymbol{n}=\mathbf{1 0})\end{array}$ & $\begin{array}{c}\mathbf{H O C l}+\mathbf{P T U} \\
(\boldsymbol{n}=\mathbf{1 0})\end{array}$ & \\
\hline $\mathrm{TSH}(\mathrm{ng} / \mathrm{ml})$ & $1.2 \pm 0.4$ & $1.1 \pm 0.5$ & $5.4 \pm 0.3$ & ${ }^{*} P<0.001$ \\
\hline $\mathrm{T}_{3}(\mathrm{nM})$ & $2.8 \pm 0.1$ & $2.9 \pm 0.2$ & $0.8 \pm 0.5$ & ${ }^{*} P<0.001$ \\
\hline $\mathrm{T}_{4}(\mathrm{n} M)$ & $58.8 \pm 15.3$ & $60.7 \pm 18.1$ & $19.3 \pm 2.1$ & ${ }^{*} P<0.001$ \\
\hline
\end{tabular}

compared with the other groups, as shown by the significant decrease in total triiodothyronine $\left(\mathrm{TT}_{3}\right)$ and thyroxine $\left(\mathrm{TT}_{4}\right)$ and the increase in $\mathrm{TSH}$ serum levels (Table 1).

\section{Propylthiouracil administration prevents dermal fibrosis in HOCl-injected mice}

At the end of the experiment, the histologic examination of Masson trichrome-stained skin sections of $\mathrm{HOCl}$-treated mice ( $\mathrm{HOCl}$ group, $n=10$ ), $\mathrm{HOCl}$ plus
PTU-treated mice (PTU group, $n=10$ ), and vehicle alone (Sham group, $n=5$ ) demonstrated that $\mathrm{HOCl}$ induces dermal fibrosis, as expressed by the increase in dermal thickness, compared with Sham. Moreover, skin samples of $\mathrm{HOCl}$ - and PTU-treated mice were strikingly protected from $\mathrm{HOCl}$-induced dermal fibrosis. The simultaneous administration of $\mathrm{HOCl}$ and $\mathrm{P}_{1} \mathrm{O}$ prevented the increase in dermal thickness $i \mathrm{lo}$ d by HOCl. (Figure 1). In addition, the PTU grou had a reduced presence of myofibroblasts, 2 determin a by $\alpha$-SMA staining when compared with th HOC group. (Figure 2).

\section{Propylthiouracil treatment prevent $\mathrm{HOCl}$-inc'uced} pulmonary fibrosis

We next investigated .he $r$ PTU affects $\mathrm{HOCl}-$ induced pulmonary $f$ sis. At re end of the experimental procedure, mos of the alveolar walls were

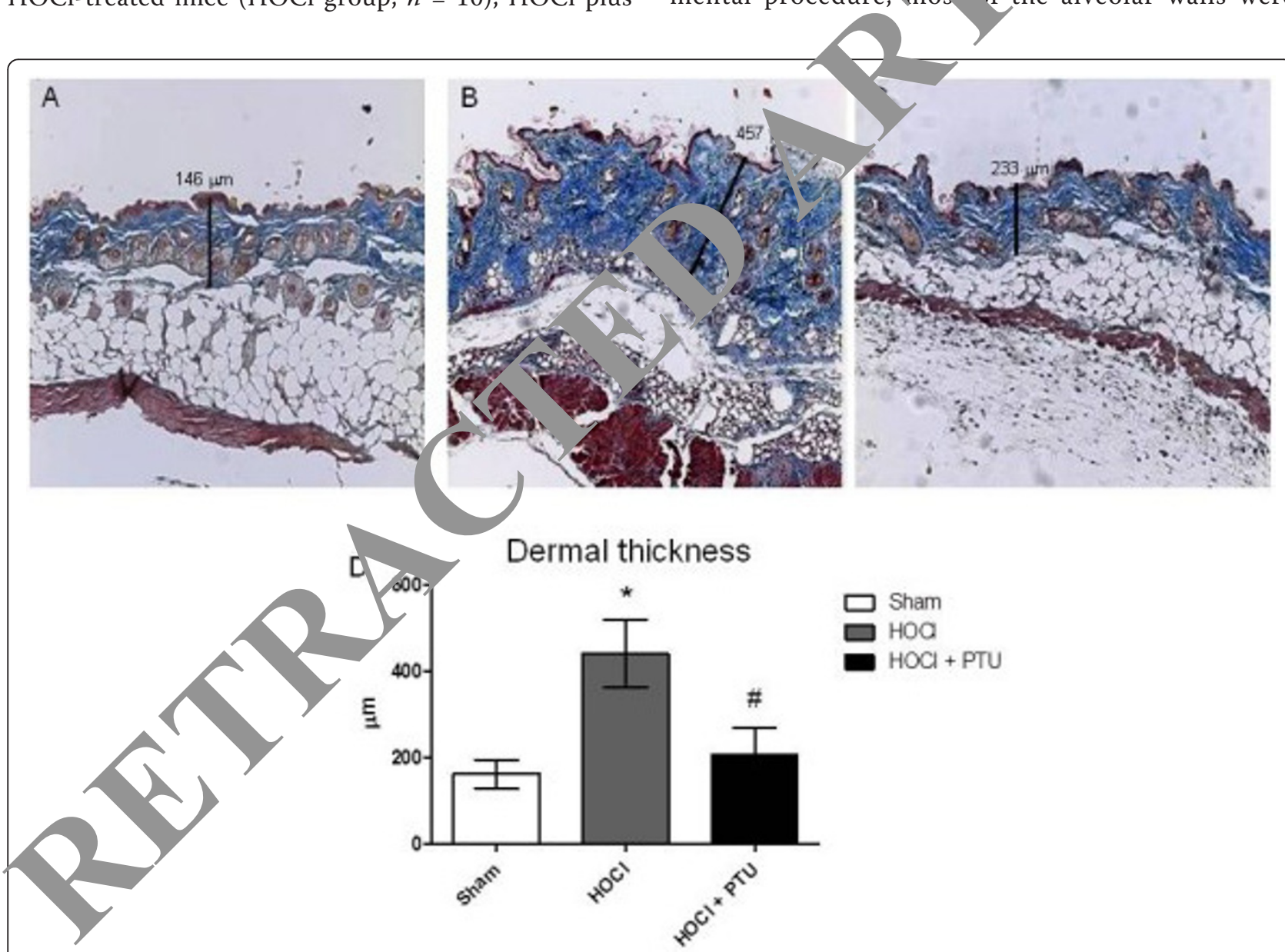

Figure 1 Accumulation of collagen in experimental dermal fibrosis is prevented by propylthiouracil administration. Dermal thickness was determined by using photomicrographs of Masson-stained sections, by measuring the distance between the epidermal-dermal junction and the dermal-fat junction at 10 randomly selected sites/high-power field (HPF), for 10 HPFs per section. Skin fibrosis was induced in mice by subcutaneous injection of $\mathrm{HOCl}$. The resultant increase in dermal thickness was significantly reduced by subcutaneous injection of propylthiouracil. Representative Masson trichrome-stained sections were examined with light microscopy: (A) Normal histology of a representative skin tissue obtained from a Sham mouse; (B) Representative histology of skin tissue of HOCl mice; (C) Representative histology of skin tissue of $\mathrm{HOCl}+$ PTU mouse (original magnification, $\times 10$ ); (D) Dermal thickness in mice from the three experimental groups (Sham group, $n=5 ; \mathrm{HOCl}$ group, $n=10 ; \mathrm{HOCl}+$ PTU group, $n=10$ ). Values are expressed as the mean and SD. ${ }^{*} P<0.001$ versus Sham \#P<0.001 versus HOCl. 


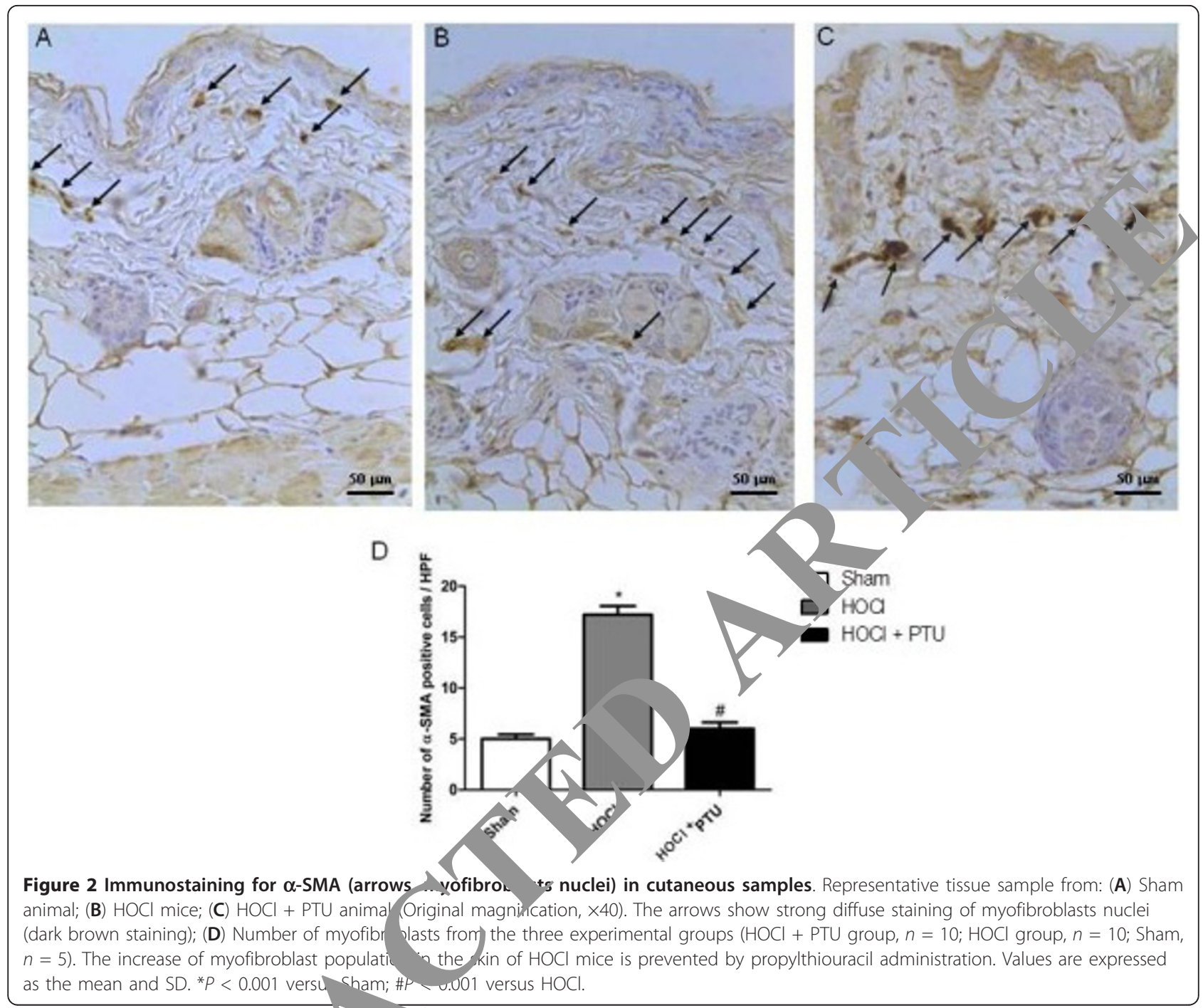

thickened, the air sp deposition in the lungs ras markedly present. Semiquantitative as ment by using the Ashcroft score demonstrated that degree of pulmonary fibrosis in the HOC $(n=10)$ was significantly higher than in the Sham ( $n$ gro p. In contrast, pulmonary fibrosis was pre ed in PTU $(n=10)$ group (Figure 3). Myofi$b$ bla -differentiation, as determined by $\alpha$-SMA staining purmonary tissues, was less evident in the PTU than is the HOCl mice (Figure 4).

High levels of VEGF, p-ERK, RAS, and RHO in cutaneous and pulmonary tissues of $\mathrm{HOCl}$-treated mice are reduced by propylthiouracil treatment

Higher amounts of VEGF, p-ERK, RAS, and RHO proteins were found both in the skin (Figure 5) and in the lungs (Figure 6) of $\mathrm{HOCl}$ compared with Sham mice, as demonstrated with Western blot analyses. Treatment with PTU significantly reduced the expression of these proteins. No significant difference in the expression of TGF- $\beta$ (data not shown) was observed in mice exposed to $\mathrm{HOCl}$ versus Sham mice or between $\mathrm{HOCl}$ and PTU mice.

Myeloperoxidase activity is reduced by PTU administration To evaluate whether PTU could affect the activity of other peroxidases, than thyroid, pulmonary myeloperoxidase (MPO) activity was tested. This peroxidase, which is itself involved in the production of $\mathrm{HOCl}$ and in the oxidative burst, was highly activated in $\mathrm{HOCl}$-treated mice, and significantly reduced by PTU concomitant administration (Figure 7).

\section{Discussion}

Free radical-mediated oxidative stress has been implicated in the etiopathogenesis of several autoimmune disorders [26]. It seems plausible that in SSc, free radicals contribute to vascular damage and jeopardize the 


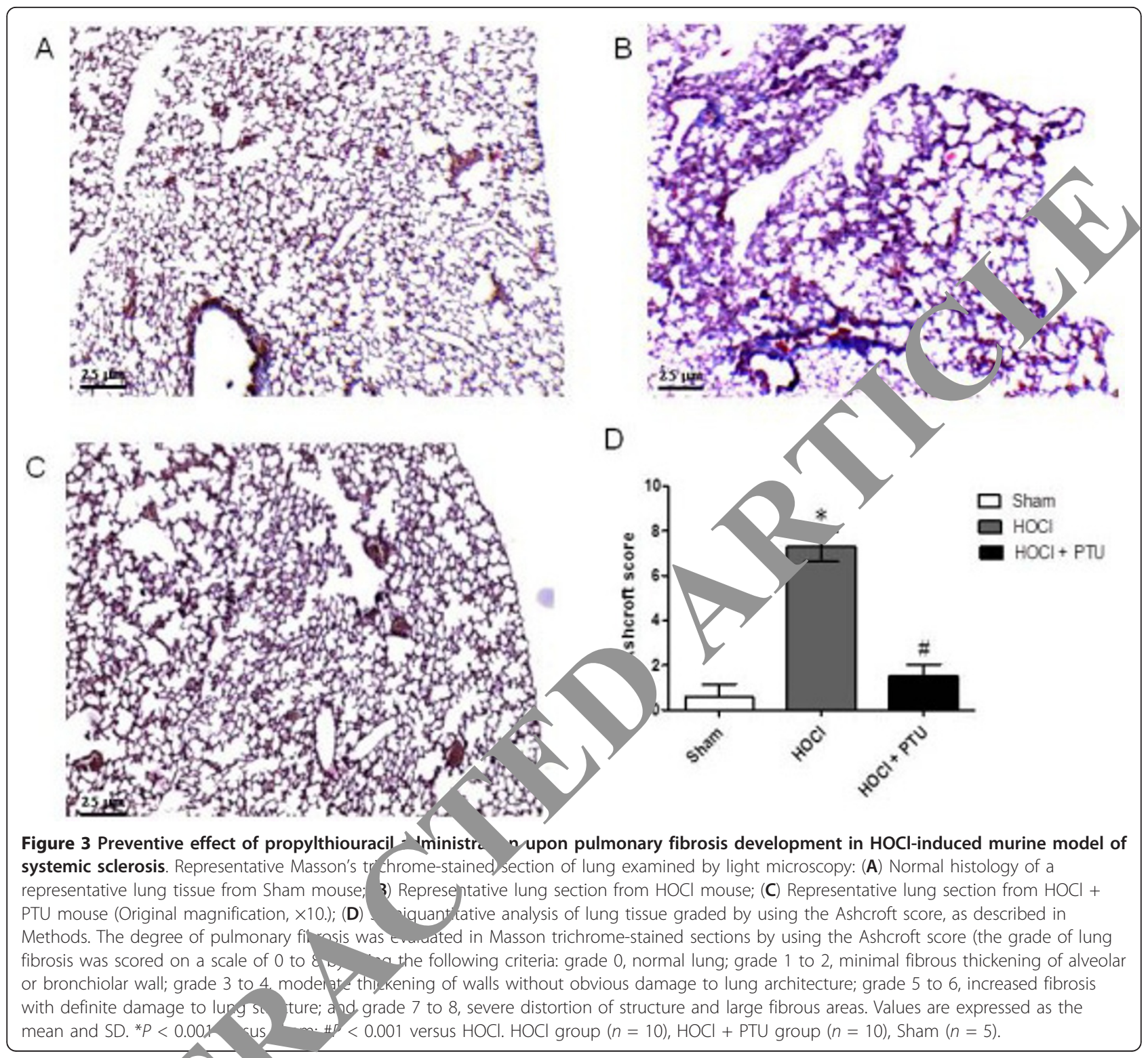

Figure 3 Preventive effect of propylthiouracil - Vministr. nupon pulmonary fibrosis development in HOCl-induced murine model of systemic sclerosis. Representative Masson's tr throme-stained) section of lung examined by light microscopy: (A) Normal histology of a representative lung tissue from Sham mouse; 3) Represelntative lung section from $\mathrm{HOCl}$ mouse; (C) Representative lung section from $\mathrm{HOCl}+$ PTU mouse (Original magnification, $\times 10$.); (D) _ iquantrative analysis of lung tissue graded by using the Ashcroft score, as described in Methods. The degree of pulmonary fil" 'osis was tvunuated in Masson trichrome-stained sections by using the Ashcroft score (the grade of lung fibrosis was scored on a scale of 0 to 8 wo the following criteria: grade 0 , normal lung; grade 1 to 2 , minimal fibrous thickening of alveolar or bronchiolar wall; grade 3 to 4 moderte thyekening of walls without obvious damage to lung architecture; grade 5 to 6 , increased fibrosis with definite damage to lung sa ture; and grade 7 to 8 , severe distortion of structure and large fibrous areas. Values are expressed as the

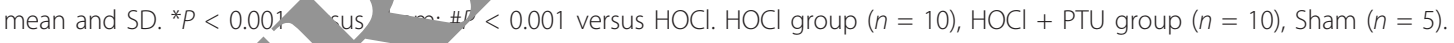

function of the ena helial system, leading to immune system ir volvement and to fibroblast activation and eventuall, ctssu fibrosis [27].

$\mathrm{U} r \mathrm{ro} / \mathrm{conditions,} \mathrm{the} \mathrm{antioxidant} \mathrm{system} \mathrm{of}$ t sk -nrotects cells against oxidative injury and prever the production of oxidation products, such as 4hydro,,-2 -nonenal or malonaldehyde, which are able to induce protein damage, apoptosis, or release of proinflammatory mediators, such as cytokines [28].

Hypochlorous acid ( $\mathrm{HOCl})$, the oxygen-reactive species we used to induce systemic sclerosis in our model and the major strong oxidant produced by myeloperoxidase, reacts readily with free amino groups to form $\mathrm{N}$ chloramines [29]. $\mathrm{HOCl}$ and $\mathrm{N}$-chloramines are unstable intermediates that can oxidize thiol groups and cause damage to cells [30]. Plasma thiol concentrations are reduced in patients with SSc compared with controls, suggestive of increased free radical production, and these reduced thiol levels were found in association with white blood cell activation [31]. PTU is a thiol-derived drug, and it could act as an exogenous source of plasma thiols contributing to reduction in the damage mediated by reactive oxygen species. The protective effects of PTU against liver damage, due to its antioxidant activity, have already been reported [32]. Our results show that PTU-treated mice are protected from $\mathrm{HOCl}$-induced damage in the skin (Figure 1). In patients with psoriasis, PTU has been used because of its antioxidant potential and also antiproliferative and immunomodulatory effect [33]. 


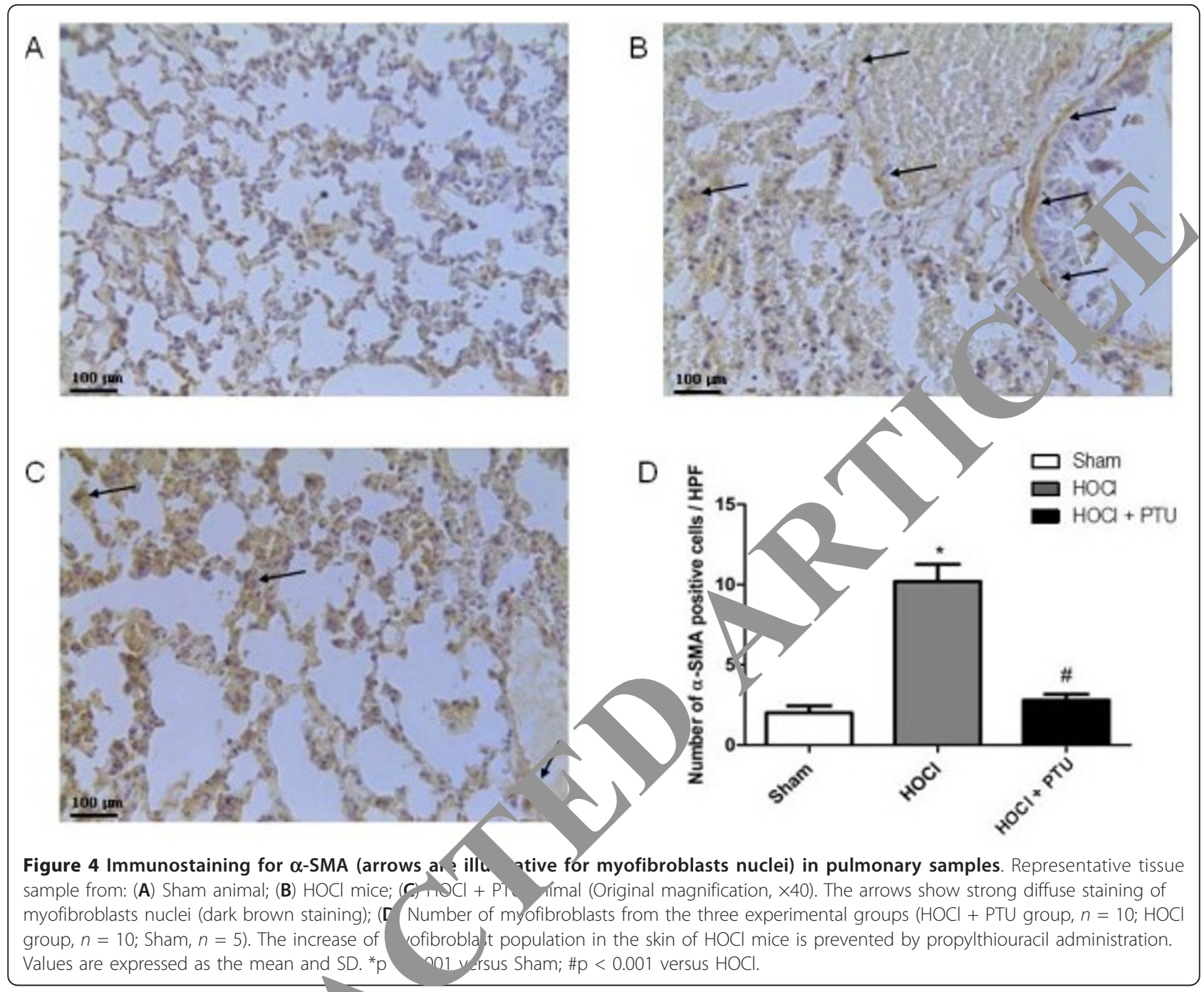

Our study also showe t $\mathrm{HCCl}$-induced pulmonary fibrosis is prevented PJ tregment (Figure 3). Our findings show tha MP ctivity is highly activated in $\mathrm{HOCl}$-treated $n$ and co, 1 sequently, PTU administration decreaced its a vity in the lungs. MPO catalyzes the form tion of hypochlorous acid ( $\mathrm{HOCl})$, a potent bactericia gent that is capable of oxidizing and chlorinat: bro pectrum of biomolecular species [34]. 5 era ctudies have shown its involvement in oxidative stru and inflammation [35], supporting the central role in the -onnection between ROS and fibrosis. In cystic fibrosis patients, it has been recently proposed to use thiol-containing molecules as antioxidants, to counteract the MPO system and therefore lung injury [36]. Previous reports showed that propylthiouracil treatment decreases the susceptibility to oxygen radical-induced lung damage in newborn rats exposed to prolonged hyperoxia [37], addressing a role in pulmonary $\mathrm{HOCl}-$ induced fibrosis for PTU.
This role may be related to the inhibition of thyroid hormone production, effect on $\mathrm{O}_{2}$ metabolism, or its direct antioxidant properties. In an animal model of multiorgan failure after a major burn, PTU-induced hypothyroidism reduced oxidative damage in the hepatic, gastric, and ileal tissues, probably due to hypometabolism, which is associated with decreased production of reactive oxygen metabolites and enhancement of antioxidant mechanisms [38].

In this setting, another study demonstrated that hypothyroidism reduced oxidant stress in kidney and testis tissues, and short-term, high-dose thyroxine administration restored oxidant stress in the same tissues of rats [39].

Moreover, $\mathrm{T}_{3}$-induced hyperthyroidism stimulated oxidative damage in rat muscle [40], whereas in hepatic stellate cells (HSCs) isolated from rats treated with thioacetamide (TAA), triiodothyronine $\left(\mathrm{T}_{3}\right)$ and L-thyroxine $\left(\mathrm{T}_{4}\right)$ enhanced activation of HSC 


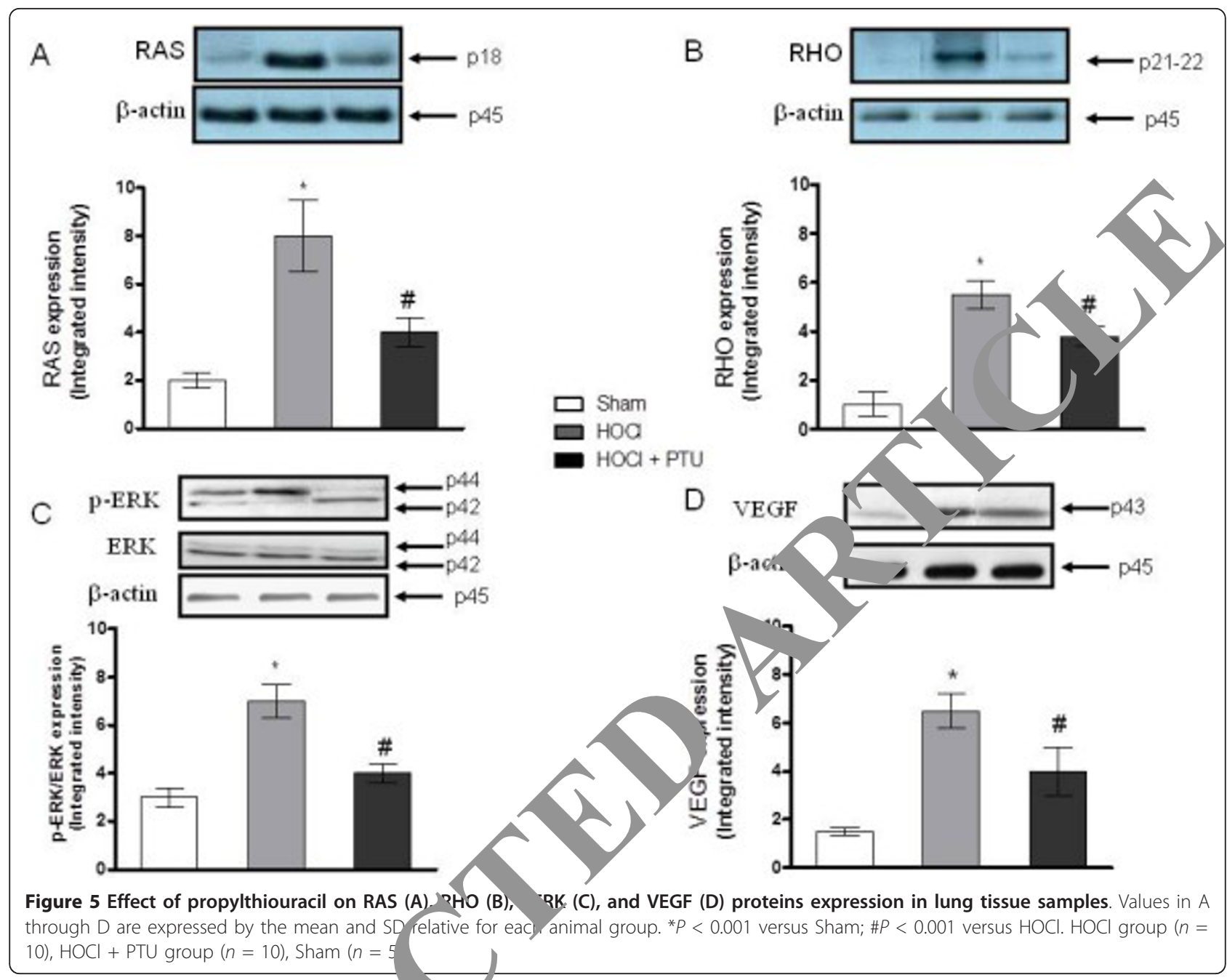

and their transdifferentiation myofibroblasts through activation of Pin In $v i v o$, the administration of $\mathrm{T}_{3}$ or $\mathrm{T}_{4}$ togetb wi $\mathrm{T}_{\mathrm{A}} \mathrm{A}$ enhances hepatic fibrosis after 3 weeks, npared with the TAA-treated group, acc $\alpha$ anied $y$ increased $\alpha$ SMA expression in $\mathrm{T}_{3}$ - and 1 reated groups [41], whereas in another study, hepatic fibrosis was significantly reduced nypo hyroid rats, either chemically and sur ly ined, as compared with euthyroid con$+\mathrm{I}_{\mathrm{S}}$, nd was aggravated in TAA-treated hyperthyroia ts [42].

In $S_{3}$ - patients, hypothyroidism, either clinical or subclinical, has been frequently reported [43], theoretically representing a counterregulatory mechanism against reactive oxygen species damage. In contrast, patients with hyperthyroidism exhibit increased levels of malondialdehyde and myeloperoxidase (MPO) activity in comparison with controls [44]. Treatment with PTU attenuated these increments after 1 month [45]. It has also been shown that PTU can substitute for glutathione as a substrate in glutathione $S$-transferase catalyzed reactions [46].

Our findings imply a central role for ERK-mediated (Figures 5,6 ) pathways in the connection between thyroid disease and systemic sclerosis, further supported by the demonstration that the inhibition of Rho and Ras can be associated with amelioration of the fibrotic component present in the disease model based on reactive oxygen species injury. Rho kinase cascade has been shown to be directly involved in the production of collagen by cardiac fibroblasts [47]. A previous report showed that blocking the Ras/MEK/ERK signaling could abolish this fibrotic response in vitro [48]. More interestingly, the inhibition of RhoA target protein, Rhokinase (ROCK), may interrupt signaling pathways known to contribute to pulmonary fibrosis, as already evidenced in bleomycin-induced experimental pulmonary fibrosis [49].

In response to normal tissue injury, fibroblasts migrate into the wound, where they synthesize and remodel new 


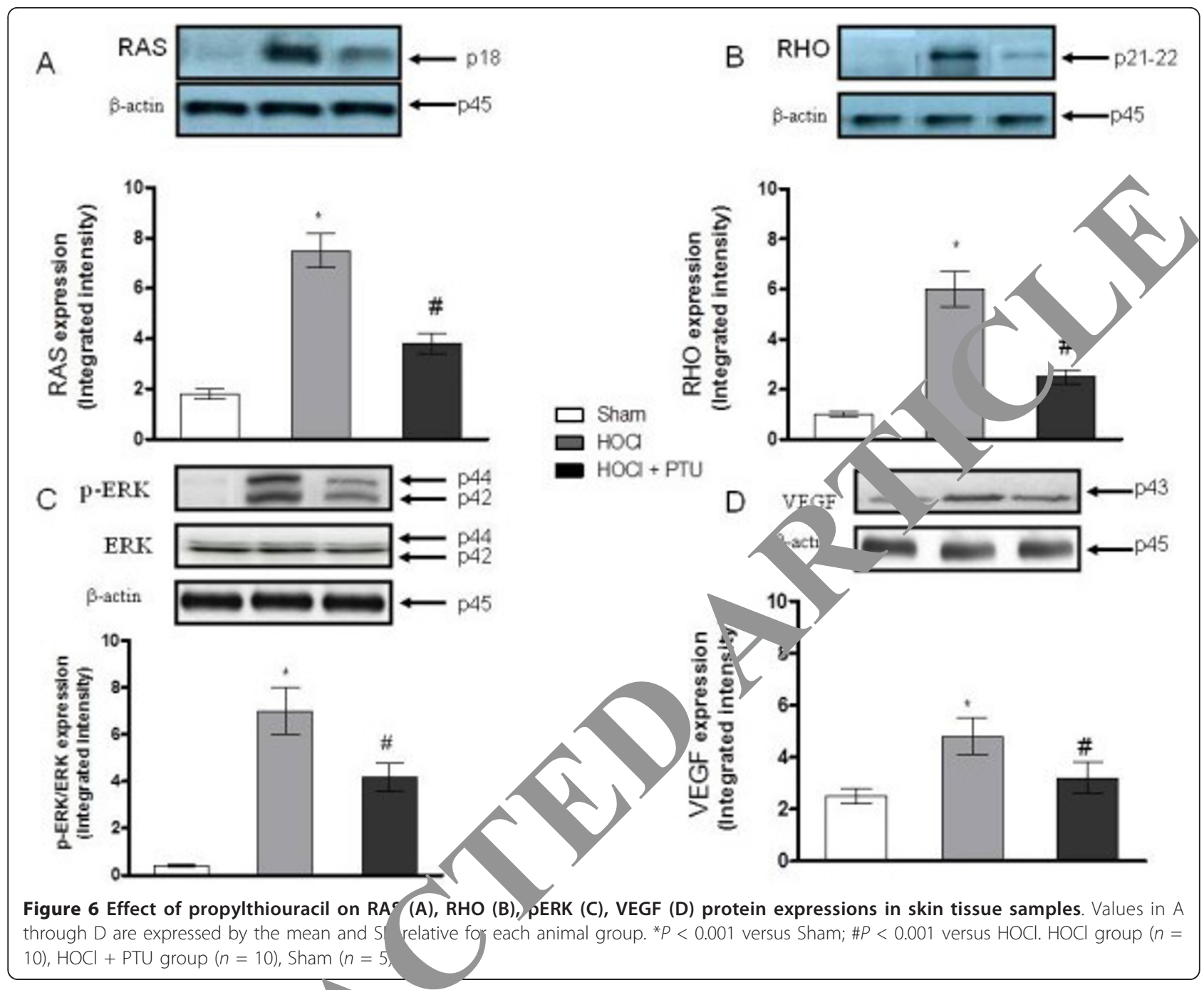

extracellular matrix. The broblust responsible for the process of wound be ing alled the myofibroblast, which expresses the hig contractile protein $\alpha$-smooth muscle actin (c- MA). Ab, ormal myofibroblast activation is a ke featur f fibrotic diseases, including SSc [50]. It y as recently aemonstrated that blocking ROS with $N$-a cys ene alleviates the elevated contractile and grato capability of lesional SSc dermal fibrob cts 511 consistent with our results (Figure 2). Postmo. $m$ analyses in different stages of SSc lung fibrosis showe that the induction of a large number of smooth muscle $\alpha$-actin-positive myofibroblasts interstitially characterize, together with overdevelopment of capillary microvessels, the early phase of tissue damage. Our results show that myofibroblast proliferation in the lung is prevented by PTU treatment (Figure 3).

In addition to fibroblast hyperproliferation and collagen hyperproduction, SSc is characterized by vascular abnormalities. One of the predominant growth factors associated with vascular endothelial proliferation, survival, and migration is VEGF [52]. Several groups of investigators have reported that VEGF is upregulated in skin of patients affected by SSc, consistent with our results $[53,54]$. VEGF could be considered another prooxidative factor when coupled with NOX-4.

An alternative hypothesis is that PTU operates in part at least through a conventional thyroid hormonemediated mechanism similar the mechanism through ERK, as ascribed to PTU in a rat model of primary pulmonary hypertension [55]. In that model, the thyroidhormone mechanism was confirmed by thyroidectomy (with no opportunity for antioxidant effect) as well as by PTU. It long has been known that epidemiologic data support a link between both SSc and pulmonary hypertension and thyroid abnormality [56,57]. Clinical trials focusing on patients affected by hyperthyroidism demonstrated that they tend to have elevated pulmonary arterial pressures that are normalized under treatment 


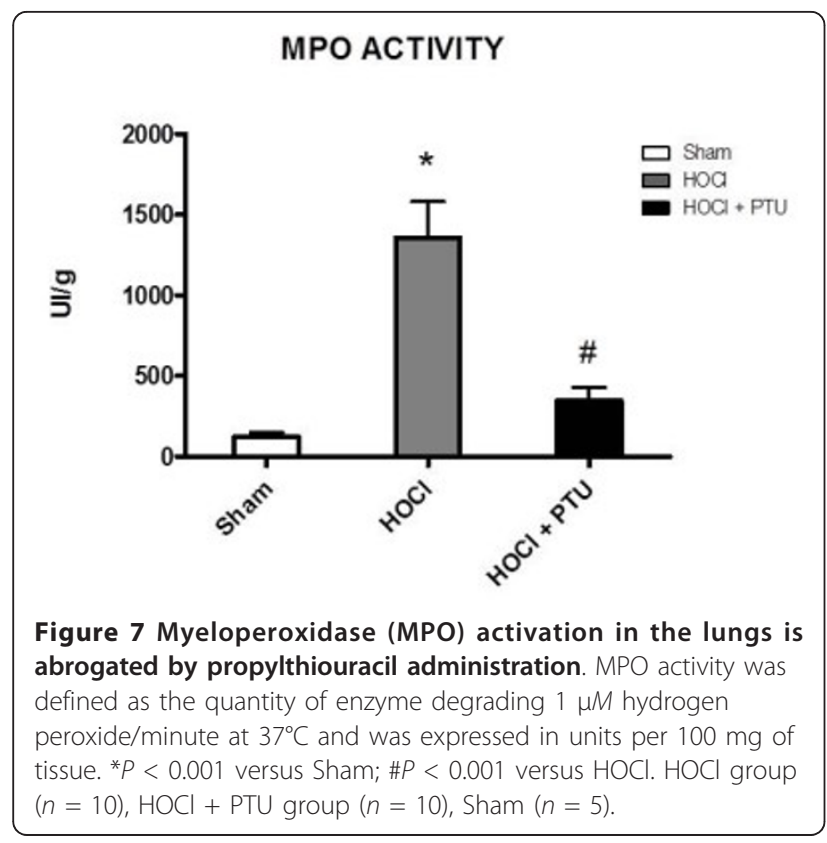

with thyroid-suppressive therapy [58-60]. These data support the hypothesis that thyroid abnormalities in humans function permissively to facilitate the disease, as demonstrated in the rat model of pulmonary hypertension.

\section{Conclusions}

Although thyroid-function alterations [10-1 4,2 are frequently reported in SSc patients, our d suge that PTU exerts an antioxidant effect, cr hsistent with previous reports [31-33,36,37], abrogatil the de relopment of cutaneous and pulmonary fibros his animal model of systemic sclerosis. T core, further studies will be needed to determine wha proportion of the protective PTU effect is reiate to th inhibition of oxidant stress or oxidant stres nyofibroblast differentiation, and coul be po tially captured clinically by an antioxidan th ment ess complex than PTU, and what propertion of $\mathrm{t}$ protective effect is through thyroid horn ne mechanisms. This latter would have to be captured icall by focusing on the intracellular signaing athn, , rather than by blocking thyroid hor-

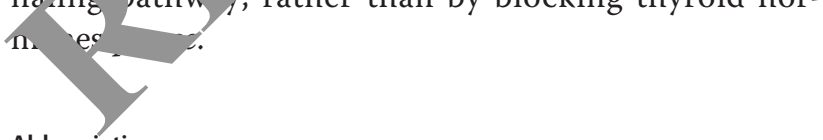

\section{Abbreviations}

AITD: autoimmune thyroid disease; a-SMA: a-smooth muscle actin; EDTA: ethylenediaminetetraacetic acid; ERK: extracellular signal-related kinase; H\&E: hematoxylin and eosin; HOCl: hypochlorous acid; HSC: hepatic stellate cells; $\mathrm{KH}_{2} \mathrm{PO}_{4}$ : potassium hydrogen phosphate; MEK: MAPK and extracellular signalrelated kinase; MPO: myeloperoxidase; $\mathrm{NaClO}$ : sodium hypochlorite; NF-kB: nuclear factor kappa-light-chain-enhancer of activated B cells; PBS: phosphate buffered saline; PTU: propylthiouracil; PVDF: polyvinylidene difluoride; Ras: rat sarcoma protein; Rho: Ras homolog gene family; ROCK: Rho-associated protein kinase; ROS: reactive oxygen species; SDS: sodium dodecylsulfate; SSc: systemic sclerosis; TAA: thioacetamide; TBS: tris-buffered saline; TGF- $\beta$ : transforming growth factor $\beta$; TSH: thyroid-stimulating hormone; $\Pi_{3}$ : total triiodothyronine; $\Pi_{4}$ : total thyroxine; VEGF: vascular endothelial growth factor.

\section{Competing interests}

The authors declare that they have no competing interests.

\section{Authors' contributions}

GLB conceived and designed the study, participated in acqui analysis and interpretation of data, and drafted the manuscript. GP performed the animal study and histologic and molecular ana participated in acquisition of data, analysis and interp tation of data, nd revision of the manuscript. DS, CM, MA, and DA contr ed to ar yysis and interpretation of data and the revision of the manuscript. IR contributed to conception and design of the study and vised the mar cript critically for important intellectual content. GFB, AS, a FS contriputed to the design and coordination of the study, analysis and in pretatich of data, and revision of the manuscript. All authors ano oved the final manuscript.

\section{Authors' details}

${ }^{1}$ Department of Clinical and Experin alyedicine, Division of Internal Medicine, University $\pi$ ina, Via Consolare Valeria $n^{\circ} 1,98100$, Messina, Italy. ${ }^{2}$ Department linis and Experimental Medicine, Division of Pharmacology, Unive, Or ivicsorna, Via Consolare Valeria $n^{\circ} 1,98100$, Messina, Italv. ${ }^{3}$ Departm of Clinical and Experimental Medicine, Division of Rheumatd Universi.y of Messina, Via Consolare Valeria n¹, 98100, Messina, Italy. ${ }^{4}$ De ent of Internal Medicine, Division of Rheumatology, University of Li aisville, Louisville, KY 40292, Kentucky, USA.

Reu d: 17 January 2013 Revised: 5 July 2013

Accep t: 16 September 2013 Published: 16 September 2013

Rt ences

Wei J, Bhattacharyya S, Tourtellotte WG, Varga J: Fibrosis in systemic sclerosis: emerging concepts and implications for targeted therapy. Autoimmun Rev 2011, 10:267-275.

2. Gabrielli A, Svegliati S, Moroncini G, Pomponio G, Santillo M, Avvedimento EV: Oxidative stress and the pathogenesis of scleroderma: the Murrell's hypothesis revisited. Semin Immunopathol 2008, 30:329-337.

3. Dooley A, Shi-Wen X, Aden N, Tranah T, Desai N, Denton CP, Abraham DJ, Bruckdorfer R: Modulation of collagen type I, fibronectin and dermal fibroblast function and activity, in systemic sclerosis by the antioxidant epigallocatechin-3-gallate. Rheumatology (Oxford) 2010, 49:2024-2036.

4. Dooley A, Bruckdorfer KR, Abraham DJ: Modulation of fibrosis in systemic sclerosis by nitric oxide and antioxidants. Cardiol Res Pract 2012, 12:521958.

5. Tsou PS, Talia NN, Pinney AJ, Kendzicky A, Piera-Velazquez S, Jimenez SA, Seibold JR, Phillips K, Koch AE: Effect of oxidative stress on protein tyrosine phosphatase $1 \mathrm{~B}$ in scleroderma dermal fibroblasts. Arthritis Rheum 2012, 64:1978-1989.

6. Pennell LM, Galligan CL, Fish EN: Sex affects immunity. J Autoimmun 2012, 38:J282-J291.

7. Soldano S, Montagna P, Brizzolara R, Sulli A, Parodi A, Seriolo B, Paolino S, Villaggio $B$, Cutolo M: Effects of estrogens on extracellular matrix synthesis in cultures of human normal and scleroderma skin fibroblasts. Ann N Y Acad Sci 2010, 1193:25-29.

8. Antonelli A, Ferri C, Fallahi P, Cazzato M, Ferrari SM, Sebastiani M, Ferrannini E: Clinical and subclinical autoimmune thyroid disorders in systemic sclerosis. Eur J Endocrinol 2007, 156:431-437.

9. Hudson M, Rojas-Villarraga A, Coral-Alvarado P, López-Guzmán S, Mantilla RD, Chalem P, Canadian Scleroderma Research Group, Colombian Scleroderma Research Group, Baron M, Anaya JM: Polyautoimmunity and familial autoimmunity in systemic sclerosis. J Autoimmun 2008, 31:156-159.

10. Anzai H, Tajima S: Systemic scleroderma associated with Graves' disease. J Dermatol 1996, 23:896-898.

11. Nicholson D, White S, Lipson A, Jacobs RP, Borenstein DG: Progressive systemic sclerosis and Graves' disease: report of three cases. Arch Intern Med 1986, 146:2350-2352. 
12. Punzi L, Betterle C: Chronic autoimmune thyroiditis and rheumatic manifestations. Joint Bone Spine 2004, 71:275-283.

13. Cianfarani F, Baldini E, Cavalli A, Marchioni E, Lembo L, Teson M, Persechino S, Zambruno G, Ulisse S, Odorisio T, D'Armiento M: TSH receptor and thyroid-specific gene expression in human skin. J Invest Dermatol 2010, 130:93-101

14. Messarah M, Saoudi M, Boumendjel A, Boulakoud MS, Feki AE: Oxidative stress induced by thyroid dysfunction in rat erythrocytes and heart. Environ Toxicol Pharmacol 2011, 31:33-41.

15. Servettaz A, Goulvestre C, Kavian N, Nicco C, Guilpain P, Chéreau C, Vuiblet V, Guillevin L, Mouthon L, Weill B, Batteux F: Selective oxidation of DNA topoisomerase 1 induces systemic sclerosis in the mouse. J Immunol 2009, 182:5855-5864.

16. Starkey KJ, Janezic A, Jones G, Jordan N, Baker G, Ludgate M: Adipose thyrotrophin receptor expression is elevated in Graves' and thyroid eye diseases ex vivo and indicates adipogenesis in progress in vivo. $J \mathrm{Mol}$ Endocrinol 2003, 30:369-380.

17. Wang YY, Morimoto S, Du CK, Lu QW, Zhan DY, Tsutsumi T, Ide T, Miwa Y, Takahashi-Yanaga F, Sasaguri T: Up-regulation of type 2 iodothyronine deiodinase in dilated cardiomyopathy. Cardiovasc Res 2010, 87:636-646.

18. Dunn TB, Malmgren RA, Carney PG, Green AW: Propylthiouracil and transfusion modifications of the effects of the Rauscher virus in BALB/C mice. J Natl Cancer Inst 1966, 36:1003-1025.

19. Dagogo-Jack S: Testosterone regulates epidermal growth factor levels in the thyroid gland of hypothyroid mice. Endocr Res 1992, 18:201-212.

20. Klecha AJ, Genaro AM, Lysionek AE, Caro RA, Coluccia AG, Cremaschi GA: Experimental evidence pointing to the bidirectional interaction between the immune system and the thyroid axis. Int I Immunopharmacol 2000, 22:491-500.

21. Li YJ, Azuma A, Usuki J, Abe S, Matsuda K, Sunazuka T, Shimizu T, Hirata Y, Inagaki H, Kawada T, Takahashi S, Kudoh S, Omura S: EM703 improves bleomycin-induced pulmonary fibrosis in mice by the inhibition of TGFbeta signaling in lung fibroblasts. Respir Res 2006, 7:16.

22. De Langhe E, Vande Velde G, Hostens J, Himmelreich U, Nemery B, Luyten FP, Vanoirbeek J, Lories RJ: Quantification of lung fibrosis an emphysema in mice using automated micro-computed tomogr. PLoS One 2012, 7:e43123.

23. Akhmetshina A, Dees C, Pileckyte M, Maurer B, Axmann R, a gel A Zwerina J, Gay S, Schett G, Distler O, Distler JH: Dual inb oit it c-abl and PDGF receptor signaling by dasatinib and nilot inid for $t$ treatment of dermal fibrosis. FASEB J 2008, 22:22 4-2222.

24. Skhirtladze C, Distler O, Dees C, Akhmetshina A Busch N, Venalis $P$, Zwerina J, Spriewald B, Pileckyte M, Schett G, D $\mathrm{JH}$ : Src linases in systemic sclerosis: central roles in fibroblast act $n$ ar d in skin fibrosis. Arthritis Rheum 2008, 58:1475-1

25. Ashcroft T, Simpson JM, Timbrell V: Simir and of estimating severity of pulmonary fibrosis on a numencal), cale. J Clin Pathol 1988, 41:467-470.

26. Ortona E, Margutti P, Mat re P. manconi r, Malorni W: Redox state cell death and autoimmune dis s: a yuder perspective. Autoimmun Rev 2008, 7:579-584

27. Herrick AL, Maty CC inic M: The emerging problem of oxidative stress and the role of antion ts in systemic sclerosis. Clin Exp Rheumatol 2001, 19:4 8.

28. Brigan - Pid rdo M: Antioxidant activity, lipid peroxidation and skin diseases. at's ne J Eur Acad Dermatol Venereol 2003, 17:663-669.

29. ners $\mathrm{A}$ organ PE, Davies MJ, Hawkins CL: Identification of plasma pro ns that e susceptible to thiol oxidation by hypochlorous acid nd amines. Chem Res Toxicol 2008, 21:1832-1840.

30. mas EL, Grisham MB, Jefferson MM: Cytotoxicity of chloramines. Me. is Enzymol 1986, 132:585-593.

31. Lau CS, O'Dowd A, Belch JJ: White blood cell activation in Raynaud's phenomenon of systemic sclerosis and vibration induced white finger syndrome. Ann Rheum Dis 1992, 51:249-252.

32. Hicks M, Wong LS, Day RO: Antioxidant activity of propylthiouracil. Biochem Pharmacol 1992, 43:439-444.

33. Utaş S, Köse K, Yazici C, Akdaș A, Keleștimur F: Antioxidant potential of propylthiouracil in patients with psoriasis. Clin Biochem 2002, 35:241-246.

34. Eiserich JP, Hristova M, Cross CE, Jones AD, Freeman BA, Halliwell B, van der Vliet $A$ : Formation of nitric oxide-derived inflammatory oxidants by myeloperoxidase in neutrophils. Nature 1998, 391:393-397.
35. Knaapen AM, Güngör N, Schins RP, Borm PJ, Van Schooten FJ: Neutrophils and respiratory tract DNA damage and mutagenesis: a review.

Mutagenesis 2006, 21:225-236.

36. Vasu VT, de Cruz SJ, Houghton JS, Hayakawa KA, Morrissey BM, Cross CE, Eiserich JP: Evaluation of thiol-based antioxidant therapeutics in cystic fibrosis sputum: focus on myeloperoxidase. Free Radic Res 2011, 45:165-176.

37. Rodriguez-Pierce M, Sosenko IR, Whitney P, Frank L: Propylthiouracil treatment decreases the susceptibility to oxygen radical-indy-ea Nung damage in newborn rats exposed to prolonged hyperoxiz Pedidtr Res 1994, 35:530-535.

38. Sener G, Sehirli O, Velioğlu-Oğünç A, Ercan F, Erkanli G, Gedik N, nn PL: Propylthiouracil (PTU)-induced hypothyroidism all viates burn-ing ced multiple organ injury. Burns 2006, 32:728-736.

39. Mogulkoc R, Baltaci AK, Oztekin E, Ozturk A, Givinaya A. ort-term thyroxine administration leads to lipid $p$ roxidation in al and testicular tissues of rats with hypothyro sm. Acta Blpl Aung 2005, 56:225-232.

40. Venditti P, Bari A, Di Stefano L, Dru Stro 13 on metabolic response and oxidative stres $1 \mathrm{~m}$ sker muscle from sedentary and trained rats. Free Radic Bic 2009, 46. -366

41. Zvibel I, Atias D, Phillips A, Hà Z, Oreh R: Thyroid hormones induce activation of rat henatic stellate "cythrough increased expression of p75 neurotrophi re tor and d/rect activation of Rho. Lab Invest 2010 90:674-684.

42. Oren R, Dotan I,,$\quad$ MI, Mvaravi Y, Aeed H, Barg J, Zeidel L, Bruck R, Halpern Z: Inhibition experimentally induced liver cirrhosis in rats by hypoths $-\mathrm{m}$. Hepa. ology 1996, 24:419-423.

43. Kahl LE, Meas, Klein I: Prospective evaluation of thyroid function in patients $\mathrm{W}$ ih systemic sclerosis (scleroderma). J Rheumatol 1986, 13:103-107.

ous-Kalinowska B, Zwirska-Korczala K, Kalinowski M, Kukla M, Birkner E, em J: Activity of antioxidative enzymes and concentration of $\mathrm{m}$. ondialdehyde as oxidative status markers in women with newly ragnosed Graves-Basedow disease and after thiamazole therapy leading to euthyroidism. Pol Arch Med Wewn 2008, 118:420-425. Erdamar H, Demirci H, Yaman H, Erbil MK, Yakar T, Sancak B, Elbeg S, Biberoğlu G, Yetkin I: The effect of hypothyroidism, hyperthyroidism, and their treatment on parameters of oxidative stress and antioxidant status. Clin Chem Lab Med 2008, 46:1004-1010.

46. Yamada T, Kaplowitz N: Propylthiouracil: a substrate for the glutathione $\mathrm{S}$ transferase that competes with glutathione. J Biol Chem 1980, 255:3508-3513.

47. Ding WY, Ti Y, Wang J, Wang ZH, Wang ZH, Xie GL, Shang YY, Tang MX Zhang Y, Zhang W, Zhong M: Prostaglandin F2a facilitates collagen synthesis in cardiac fibroblasts via an F-prostanoid receptor/protein kinase C/Rho kinase pathway independent of transforming growth factor $\beta 1$. Int J Biochem Cell Biol 2012, 44:1031-1039.

48. Stratton R, Rajkumar V, Ponticos M, Nichols B, Shiwen X, Black CM, Abraham DJ, Leask A: Prostacyclin derivatives prevent the fibrotic response to TGF-beta by inhibiting theRas/MEK/ERK pathway. FASEB J 2002, 16:1949-1951.

49. Jiang $C$, Huang $H$, Liu J, Wang Y, Lu Z, Xu Z: Fasudil, a rho-kinase inhibitor, attenuates bleomycin-induced pulmonary fibrosis in mice. Int $J$ Mol Sci 2012, 13:8293-8307.

50. Leask A: Towards an anti-fibrotic therapy for scleroderma: targeting myofibroblast differentiation and recruitment. Fibrogenesis Tissue Repair 2010, 3:8.

51. Shi-Wen X, Thompson K, Khan K, Liu S, Murphy-Marshman H, Baron M, Denton $C P$, Leask A, Abraham DJ: Focal adhesion kinase and reactive oxygen species contribute to the persistent fibrotic phenotype of lesional scleroderma fibroblasts. Rheumatology (Oxford) 2012, 51:2146-2154

52. Ferrara N: The role of VEGF in the regulation of physiological and pathological angiogenesis. EXS 2005, 209-231

53. Jinnin M, Makino T, Kajihara I, Honda N, Makino K, Ogata A, Ihn H: Serum levels of soluble vascular endothelial growth factor receptor-2 in patients with systemic sclerosis. Br J Dermatol 2010, 162:751-758.

54. Distler O, Distler JH, Scheid A, Acker T, Hirth A, Rethage J, Michel BA, Gay RE, Müller-Ladner U, Matucci-Cerinic M, Plate KH, Gassmann M, Gay S: Uncontrolled expression of vascular endothelial growth factor and its 
receptors leads to insufficient skin angiogenesis in patients with systemic sclerosis. Circ Res 2004, 95:109-116.

55. Al Husseini A, Bagnato G, Farkas L, Gomez-Arroyo J, Farkas D, Mizuno S, Kraskauskas D, Abbate A, Van Tassel B, Voelkel NF, Bogaard HJ: Thyroid hormone is highly permissive in angioproliferative pulmonary hypertension in rats. Eur Respir J 2012, 41:104-114.

56. Hudson M, Rojas-Villarraga A, Coral-Alvarado P, López-Guzmán S, Mantilla RD, Chalem P, Canadian Scleroderma Research Group, Colombian Scleroderma Research Group, Baron M, Anaya JM: Polyautoimmunity and familial autoimmunity in systemic sclerosis. J Autoimmun 2008, 31:156-159.

57. Marasini B, Ferrari PA, Solaro N, Selmi C: Thyroid dysfunction in women with systemic sclerosis. Ann N Y Acad Sci 2007, 1108:305-311.

58. Marvisi M, Zambrelli P, Brianti M, Civardi G, Lampugnani R, Delsignore R: Pulmonary hypertension is frequent in hyperthyroidism and normalizes after therapy. Eur J Intern Med 2006, 17:267-271.

59. Siu CW, Zhang XH, Yung C, Kung AW, Lau CP, Tse HF: Hemodynamic changes in hyperthyroidism-related pulmonary hypertension: a prospective echocardiographic study. I Clin Endocrinol Metab 2007, 92:1736-1742.

60. Guntekin U, Gunes Y, Tuncer M, Simsek H, Gumrukcuoglu HA, Arslan S, Gunes A: QTc dispersion in hyperthyroidism and its association with pulmonary hypertension. Pacing Clin Electrophysiol 2009, 32:494-499.

\section{doi:10.1186/ar4300}

Cite this article as: Bagnato et al:: Propylthiouracil prevents cutaneous and pulmonary fibrosis in the reactive oxygen species murine model of systemic sclerosis. Arthritis Research \& Therapy 2013 15:R120.

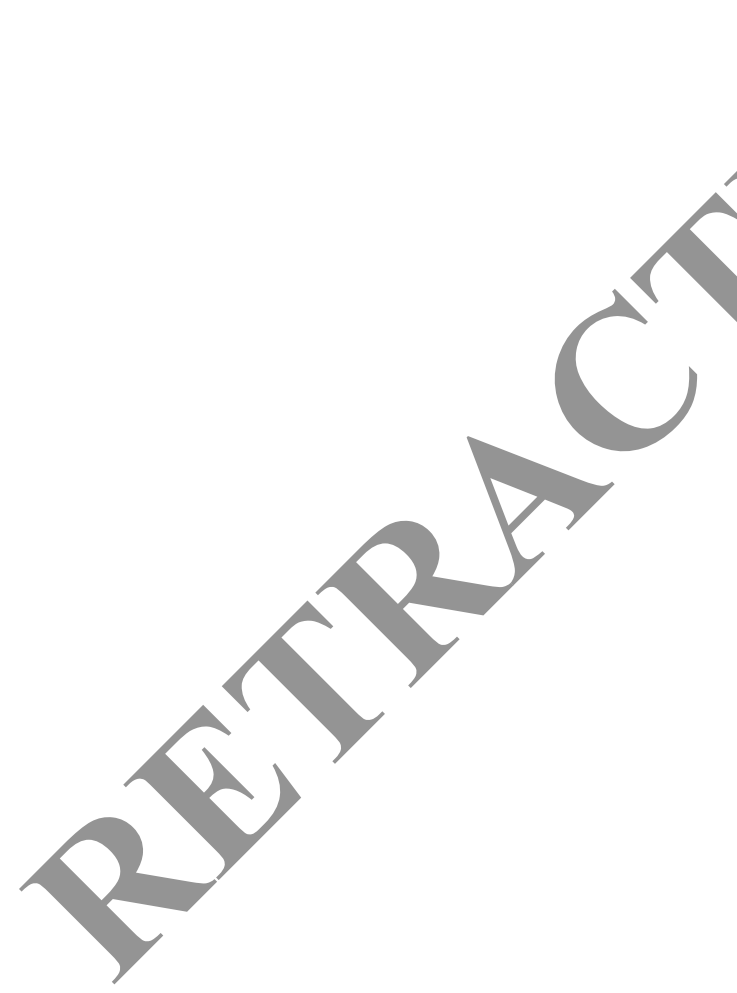

\section{Submit your next manuscript to BioMed Central and take full advantage of:}

- Convenient online submission

- Thorough peer review

- No space constraints or color figure charges

- Immediate publication on acceptance

- Inclusion in PubMed, CAS, Scopus and Google Scholar

- Research which is freely available for redistribution 